\title{
Diversification, disparification, and hybridization in the desert shrubs Encelia
}

Sonal Singhal ${ }^{1 *}$, Adam B. Roddy ${ }^{2,3}$, Christopher DiVittorio ${ }^{4,5}$, Ary Sanchez-Amaya ${ }^{6}$, Claudia L. Henriquez $^{6}$, Craig R. Brodersen ${ }^{2}$, Shannon Fehlberg $^{7}$, Felipe Zapata ${ }^{6}$

1. Department of Biology, CSU Dominguez Hills, 1000 E Victoria Street, Carson CA 90747

2. School of the Environment, Yale University, New Haven, CT 06511

3. Institute of Environment, Florida International University, Miami, FL, 33133

4. University of California Institute for México and the United States, 3324 Olmsted Hall, University of California, Riverside, CA 92521

5. Pinecrest Research Corporation, 5627 Telegraph Avenue, Suite 420, Oakland, CA 94609

6. Department of Ecology and Evolutionary Biology, University of California, Los Angeles, 612 Charles E. Young Dr. South, CA 90095

7. Research, Conservation, and Collections, Desert Botanical Garden, 1201 N Galvin Parkway, Phoenix, AZ 85008

* corresponding author: sonal.singhal1@gmail.com; (310) 243-3394

Total word count: 6320

Summary: 172

Introduction: 982

Methods: 2069

Results: 689

Discussion \& Conclusion: 2570

Figures: 5 figures, Figures 1 - 4 to appear in color

Tables: 1 table

Supplemental Information: Expanded Methods, 12 figures, and 5 tables 


\section{Summary}

- There are multiple hypotheses for the spectacular plant diversity found in deserts. We explore how different factors, including the roles of ecological opportunity and selection, promote diversification and disparification in Encelia, a lineage of woody plants in the deserts of the Americas.

- Using a nearly complete species-level phylogeny along with a broad set of phenotypic traits, we estimate divergence times and diversification rates, identify instances of hybridization, quantify trait disparity, and assess phenotypic divergence across environmental gradients.

- We show that Encelia originated and diversified recently (mid-Pleistocene) and rapidly, with rates comparable to notable adaptive radiations in plants. Encelia probably originated in the hot deserts of North America, with subsequent diversification across steep environmental gradients. We uncover multiple instances of gene flow between species. The radiation of Encelia is characterized by fast rates of phenotypic evolution, trait lability, and extreme disparity across environments and between species-pairs with overlapping geographic ranges.

- Encelia exemplifies how interspecific gene flow in combination with high trait lability can enable exceptionally fast diversification and disparification across steep environmental gradients.

\section{Keywords}

Aridity, deserts, Encelia, hybridization, phylogenomics, trait evolution 


\section{Introduction}

Despite the seemingly barren landscape of arid habitats, desert ecosystems harbor some of the most spectacular plant evolutionary radiations (Klak et al., 2004; Hernandez-Hernandez et al., 2011). Why and how aridity has promoted the diversification of plant species and phenotypes has puzzled generations of ecologists and evolutionary biologists alike (Stebbins, 1952; Axelrod, 1972), resulting in several hypotheses. First, arid habitats worldwide began to form and expand only in the last 10 my (Arakaki et al., 2011), a relatively short geological time frame during which new regions of niche space became available. Additionally, deserts have been dynamic through space and time, with diverse orogenies, glacial cycles, marine incursions, and volcanic eruptions that likely caused highly variable selection regimes, multiple cycles of migration-isolation, and eventually colonization and diversification in new habitats (Thompson \& Anderson, 2000; Riddle et al., 2000; Oskin \& Stock, 2003; Conly et al., 2005). Second, in deserts, substantial topographic, edaphic, climatic, and ecological heterogeneity results in a diversity of habitats, across which species can persist and diversify (Ellis et al., 2006; Sosa et al., 2020). Third, the environmental factors that characterize arid ecosystems typically represent extreme conditions for plant functioning and survival, including, but not limited to, drought-stress, high UV radiation, high temperature, and high salinity (Sandquist, 2014). These extreme conditions often occur over narrow geographic regions. When these multiple stressors converge, multiple, functionally equivalent solutions to the same challenge can evolve. This can lead to phenotypic disparification in otherwise seemingly homogeneous environments (Niklas, 1994).

The confluence of these geological, environmental, and ecological factors in arid ecosystems are likely crucial in spurring the radiation of resident plant lineages (Hernández-Hernández et al., 2014; Said Gutiérrez-Ortega et al., 2018), and the multiplicity of strong selective agents that occur in arid ecosystems may be responsible for the remarkable morphological and physiological diversity that have evolved among desert plants. Desert lineages, therefore, provide ideal case studies of the role of selection in plant radiations. Yet, integrative studies that link the evolutionary history of a lineage with patterns of phenotypic, ecological, climatic, and environmental variation are lacking, and thus our understanding of the processes of diversification of plants in arid regions remains elusive. Here, we use an integrative approach to 
document the evolutionary radiation of shrubs in the genus Encelia (Asteraceae), which are widespread throughout the deserts of the Americas, and showcase how multiple factors abiotic, biogeographic, phenotypic, and population dynamics - interact to produce high diversification within a clade.

Most species of Encelia are distributed in the arid lands of southwestern North America, the dry lands of Chile, Peru, and Argentina, and the (arid) Galapagos Islands (Clark, 1998). These plants inhabit various types of deserts, including inland deserts, coastal dunes, as well as high and low deserts; E. actoni even passes the frost line in the Sierra Nevada mountain range of California. Given the widespread distribution of Encelia, it is plausible that the dynamic geologic and climatic history of the arid habitats has provided multiple opportunities for lineage separation and diversification (Spotila et al., 1998; Dolby et al., 2015). Indeed, previous work has shown that range fragmentation and expansion associated with climatic changes during the Pleistocene have influenced the spatial distribution of genetic diversity in the widespread Encelia farinosa (Fehlberg \& Ranker, 2009; Fehlberg \& Fehlberg, 2017). However, the influence of biogeographic, ecological, or other abiotic forces on the radiation of the genus Encelia is unknown.

Commonly referred to as brittlebushes, Encelia species display remarkable eco-phenotypic diversity, and their phenotypic traits are strongly associated with habitat differentiation (Ehleringer \& Clark, 1988; Clark, 1998). The species range from small to medium-size shrubs (0.2 - $1.5 \mathrm{~m}$ in height) but exhibit substantial variation in overall plant architecture. Leaf morphology is exceptionally diverse in Encelia. The leaves are always simple and spirally arranged but vary extensively in shape, margin, size, and indumentum. Classic studies in plant ecophysiology have shown fitness tradeoffs between leaf morphological traits and physiological functions that are associated with fine-scale habitat differentiation (Ehleringer et al., 1981; Ehleringer, 1988). In contrast to vegetative structures, inflorescence morphology, floret morphology, and flowering phenology in Encelia do not display substantial diversity, consistent with Asteraceae more generally. Thus, much of the phenotypic diversification in Encelia occurs among vegetative structures, although the overall tempo and mode of phenotypic evolution including the rate of trait evolution and correlation in evolution across traits - in Encelia is not understood. 
As currently circumscribed, Encelia includes 15 species and 5 subspecies (Clark, 1998). Most species are allo- or parapatric, but contact zones where natural hybrids form are common throughout the geographic range of Encelia (Clark, 1998). Natural hybridization is rampant in Encelia (Kyhos, 1967; Kyhos et al., 1981), and some species are hypothesized to result from hybrid speciation (Allan et al., 1997). Nevertheless, all species seemingly maintain their phenotypic cohesion and independence. Though divergent selection can maintain species despite widespread hybridization (DiVittorio et al., 2020), whether interspecific gene flow increases genetic diversity through hybridization or introgression among Encelia species and thus enables lineages to take advantage of new ecological opportunities is not known.

Understanding the evolution of the unique ecology, phenotypic diversity, and the role of gene flow in the radiation of Encelia requires a well-resolved phylogeny of the group. Variation in morphology, secondary chemistry, and sequence data show that Encelia is monophyletic and most closely related to Gerea and Enceliopsis, however the relationships among the species in the genus have been difficult to resolve (Clark, 1998; Fehlberg \& Ranker, 2007). Here we present a broadly sampled phylogenetic analysis of Encelia using RAD seq from 12 Encelia species and 2 outgroup species. Using this phylogeny, we address four questions: a) what is the evolutionary history of Encelia? b) what is the tempo and mode of diversification and trait disparification in Encelia? c) what are the main drivers of diversification and trait disparification in Encelia? and d) what is the role of interspecific gene flow in this evolutionary radiation?

\section{Methods}

\section{Sampling}

We sampled 77 individuals from 12 of the 15 recognized species in Encelia (Fig. 1; Table S1). Where possible, we collected individuals across the range. For all species, we collected leaf and seed material during field seasons ranging from 2009 - 2016. Species were grown in a common garden at the University of California Agricultural Operations Station in Riverside, CA; further details are available in the Supplemental Methods. Phenotypic measurements and tissues for genetic analysis were taken from adult individuals in the garden for all species but Encelia ravenii and E. resinifera, for which we used field-collected adult leaves. 


\section{Genetic data collection}

We collected genetic data using double-digest restriction-aided (ddRAD) sequencing. We first extracted DNA from silica-dried adult leaves and then prepared doubly-barcoded ddRAD libraries (Peterson et al., 2012) using Pstl and Msp/ and size-selecting fragments from 250 - 700 bp. All libraries were pooled and sequenced across one lane of 100 PE sequencing on the Illumina HiSeq 4000 Sequencing Platform.

To process and analyze these data, we wrote a pipeline that generates both pseudo-reference genomes per lineage and variant call sets across individuals within a lineage. This approach generates a common reference index across lineages, making it easier to identify homologous loci and variants. Full details are in the Supplemental Information. First, we cleaned and assembled reads using Trimmomatic v36 (Bolger et al., 2014), PEAR v0.9.8 (Zhang et al., 2014), and Velvet v1.2.10 (Zerbino \& Birney, 2008). Second, we determined lineage identity per individual. Although all sampled individuals were identified to nominal species, species boundaries have not been well-tested in Encelia. To do so, we used VSEARCH v2.9.1 (Rognes et al., 2016) to identify homologous loci using a 70\% identity cutoff. We then aligned loci using mafft v7.9.34 (Katoh et al., 2009), concatenated these loci, and used RAxML v8.2.11 to generate a phylogeny from the $11.6 \mathrm{~K}$ loci, $1.5 \mathrm{Mb}$ concatenated alignment (Stamatakis, 2014). By comparing clade identity to nominal species identity, we determined likely lineage identities for each individual (Table S1). Finally, after determining lineage identities, we generated a pseudo-reference genome per lineage. To do so, we used an iterative reference-based approach (Sarver et al., 2017). Across all individuals, we selected the longest locus in each homolog group. This unique set of $244 \mathrm{~K}$ loci served as our starting pseudo-reference genome. Per lineage, we mapped reads to the starting pseudo-reference genome using bwa v0.7.17 (Li, 2013), called variants using samtools v1.5 (Li et al., 2009), and then mutated the current pseudo-reference genome to incorporate any variants at $\geq 50 \%$ allele frequency. This was repeated three additional times to result in a final pseudo-reference genome specific to the lineage. We generated the final variant set per lineage by using bwa to align reads and then calling genotypes using samtools. We retained all sites with quality scores $>20$ and all genotypes with depth $\geq 10 x$. 


\section{Genetic data analyses}

\section{Phylogenetic inference}

We inferred individual-level and lineage-level phylogenies using concatenated and coalescent-based models; full details are available in the Supplemental Information. For an individual-level phylogeny, we used RAxML to infer a phylogeny and 100 bootstrap replicates from a $31 \mathrm{~K}$ loci, $3.9 \mathrm{Mb}$ concatenated alignment. We used SVDquartets based on 2.8K SNPs to infer a coalescent-based phylogeny with 100 bootstrap replicates (Chifman \& Kubatko, 2014). Bootstrap estimates of nodal support are often inflated, particularly for phylogenomic datasets (Cummings et al., 2003). Accordingly, we calculated gene concordance factors (gCF) and site concordance factors (SCF) using IQ-TREE v1.6.4 (Minh et al., 2020), both of which better measure conflict across loci and sites.

For a lineage-level phylogeny, we used two coalescent-based approaches. First, we used ASTRAL - III (Zhang et al., 2018) based on 29K gene trees inferred using RAxML. Second, we used SVDquartets with the same SNP dataset used for the individual-level SVDquartets phylogeny (see above). Neither ASTRAL-III nor SVDquartets provides terminal branch lengths. Accordingly, we used RAxML to estimate branch lengths based on a concatenated alignment on a constrained topology. To infer a time-calibrated phylogeny, we used an external calibration from a comprehensive angiosperm phylogeny that estimated the crown age of Encelia as 1.36 million years (Myr) (Magallón et al., 2015; Smith \& Brown, 2018). This aligns with previous divergence dating based on population genomic data that inferred the crown of Encelia as 1.05 Myr (Singhal, unpublished). We used this root age to infer a chronogram using the 'chronos' function in the R package 'ape' with lambda of 0.01 . We used this time-calibrated phylogeny in all comparative analyses.

\section{Introgression}

Given previous analyses and field studies have suggested hybridization is common in Encelia (Clark \& Allan, 1997; Allan et al., 1997), we used two complementary approaches to identify likely instances of historical and current introgression. First, we inferred phylogenetic networks using SNAQ v0.9.0 (Solís-Lemus \& Ané, 2016). As input, we provided gene trees, removing 
any gene trees with $>50 \%$ missing data. We then ran SNAQ for 0 to 5 reticulate edges, for three independent replicates each, using the ASTRAL tree as the starting topology. Second, we calculated the D-statistic across lineages, which measures when topological variance is in excess of what would be predicted under incomplete lineage sorting (Durand et al., 2011). Using all possible species triads based on the ASTRAL topology with Enceliopsis covelli as the outgroup, we calculated an allele frequency based D-statistic. We then calculated significance of the D-statistic by conducting 1000 bootstraps and calculating the Z-score (Eaton \& Ree, 2013). For a given species pair, we report the D-statistic calculated using the nearest neighbor as the third lineage. If this still resulted in multiple comparisons, we conservatively report the D-statistic with the smallest Z-score (Malinsky et al., 2018).

\section{Population genetics}

Given that Encelia lineages likely radiated rapidly, genetic divergence should be similar across species comparisons. To test this prediction, we calculated $D_{x y}$ and $F_{S T}$ (Nei, 1978; Reich et al., 2009) across all pairwise lineages.

\section{Trait data collection}

We collected nine morphological and physiological traits (summarized in Table S2) across species to determine the extent and nature of phenotypic variation. In addition, we used microCT imaging to characterize the fine-scale external and internal morphology of leaves as well as to calculate trichome density and stem xylem vessel diameter and area. Below we briefly describe how these data were collected; full details are available in the Supplemental Information.

Leaf area, shape, and color

To analyze leaf area, shape, and color, we collected and photographed three to five adult leaves per individual growing in the common garden. We analyzed leaf images using Image (Rasband \& Others, 1997) and summarized leaf measurements using a scaled and centered principal component analysis. The first two axes summarize $42 \%$ and $24 \%$ of the variation respectively; PC1 largely loads on size-related measurements and PC2 largely reflects the roundness of the leaf. To measure color, we used the white-balanced leaf images in Adobe Photoshop and measured the arithmetic mean of all pixels of the largest circumscribed 
rectangle possible within the center of the leaf. Leaf mass was measured on dry leaves and used to calculate leaf mass per area (LMA).

\section{Canopy ramification and wood density}

We estimated the degree of canopy ramification as the number of terminal branch tips per stem cross-sectional area (BTSA; (Roddy et al., 2019)) on plants growing in the common garden. Wood density of stems stripped of their bark was measured using Archimedes principle by measuring the mass of water displayed on a balance and subsequently measuring the dry mass of the stems.

\section{Stem hydraulic conductance}

Whole-shoot hydraulic conductance was measured using a low pressure flow meter (Kolb et al., 1996), which enables measuring the entire shoot regardless of branch ramification and can be applied to morphologically diverse structures (Roddy et al., 2016, 2019). Measurements were taken on healthy shoots from well-watered and mature plants. Hydraulic conductance was calculated as the slope of the regression of flow rate versus pressure. Because shoots differed in size and ramification, hydraulic conductance was normalized by leaf area of the shoot, which is taken as a metric of hydraulic efficiency (Roddy et al., 2019).

\section{MicroCT imaging}

High-resolution, three-dimensional (3D) images of stem and leaf structure were obtained by performing hard X-ray microcomputed tomography (microCT) at the Advanced Light Source, Lawrence Berkeley National Laboratory (LBNL), Beamline 8.3.2 (Brodersen, 2013; Brodersen \& Roddy, 2016). Full details of image capture are available in the Supplemental Information. Mature leaves and stems were sampled from plants growing in the common garden and imaged within 48 hours. Stems were allowed to air-dry prior to microCT imaging to ensure that vessels had emptied, and leaves were kept sealed in moist plastic bags until immediately before imaging.

To characterize trichome density, digital slices parallel to the fresh leaf surface were taken through the trichomes, allowing trichomes to be counted per unit projected leaf surface area. Stem xylem vessel diameter and area were measured using ImageJ on 2D cross sections of microCT image stacks obtained from dried stems. 


\section{Spatial data collection}

To determine the geographic extent and climatic envelope of Encelia species, we downloaded all occurrence data for Encelia species from the Global Biodiversity Information Facility (GBIF) on 10 June 2019 (GBIF, 2019). Using the R package CoordinateCleaner (Zizka et al., 2019), we removed points falling in the ocean, zero coordinates, and equal coordinates and retained only those points from preserved specimens or human observations. By species, we then removed extreme spatial outliers using the 'cc_outl' function, removed duplicate records, and thinned data by 1 kilometer using the R package spThin (Aiello-Lammens et al., 2015).

Using these cleaned and thinned data, we extracted climatic and soil data using WorldClim 2.0 rasters at 30s resolution (Fick \& Hijmans, 2017) and the Unified North American Soil Map at 0.25 degree resolution (Liu et al., 2014). For climatic data, we focused on four bioclimatic variables that reflect extreme climatic conditions and are likely to be important in determining plant survival: maximum temperature of warmest month (bioclim 5), minimum temperature of coldest month (bioclim 6), precipitation of wettest month (bioclim 13), and precipitation of driest month (bioclim 14). We summarized the 18 soil variables describing soil composition and acidity using a principal component analysis (PCA) and retained the first two axes that explained $22 \%$ and $19 \%$ of the variation in total. All spatial analyses were conducted using the $R$ packages raster and rgeos (Hijmans et al., 2015; Bivand \& Rundel, 2017).

\section{Comparative analyses}

To determine net diversification rate, we used the crown age estimator across a range of extinction rates and our time-calibrated phylogeny (Magallón \& Sanderson, 2001). We explored three scenarios for extinction $(\varepsilon=0.1, \varepsilon=0.3$, and $\varepsilon=0.9)$; the parameter $\varepsilon$ reflects the balance between speciation and extinction rates.

To characterize the tempo and mode of trait evolution, we used species-level means and estimated phylogenetic signal $(\lambda)$ for each trait (Pagel, 1999), calculated the rate of trait evolution in felsens (Ackerly, 2009), and calculated disparity through time using the average squared Euclidean distance (Harmon et al., 2003). To measure correlations between traits and correlations between traits and environmental variables, we conducted phylogenetic generalized 
least squares (PGLS), using a Brownian motion correlation matrix. We used the R packages phytools, geiger, ape, nlme, and ggtree to conduct and visualize all comparative analyses (Paradis et al., 2004; Harmon et al., 2008; Pinheiro \& J, 2009; Revell, 2012; Yu et al., 2017).

To determine the biogeographic history of Encelia, we used BioGeoBEARS (Matzke, 2013) to estimate ancestral ranges. Occurrence data were mapped onto Ecological Regions of North America (Omernik \& Griffith, 2014) to assign extant species to one or more of six biogeographic areas: Baja California Deserts, Mediterranean, Mojave Desert, Sonoran Desert, the cold deserts, or Peru (Fig. S1). We ran the Dispersal-Extinction-Cladogenesis (DEC) only, given limitations of more complex models (Ree \& Sanmartín, 2018). We set the maximum possible range size to four.

We compared how species-pairs have diverged across environmental and morphological variables. For the morphological, soil, and climatic datasets, we first summarized the data using a scaled and centered principal component analysis (PCA). We then calculated species-level means across all PC axes; from these means, we calculated the Euclidean distance between all species-pairs in morphological and environmental space. For each pairwise comparison, we also determined geographic range overlap. To do this, we inferred geographic range for each species based on the alpha convex hull of species occurrence data and estimated overlap in convex hulls (Pateiro López \& Rodríguez Casal, 2010).

\section{Results}

\section{Genetic data analyses}

Our final dataset resulted in an average of $870 \mathrm{Mb}$ sequence across an average of 60K loci for 72 individuals (Table S1). We dropped five individuals that yielded $<5 \%$ of homologous loci. Using these genetic data, we first determined likely lineage assignments among all sampled individuals, finding evidence for non-monophyly of E. californica and E. virginensis (Fig. S2). We accordingly revised lineage designations in these two nominal species to reflect the presence of putative new lineages (Table S1). The individual-level phylogeny based on these new lineage designations recovers the same topology as the lineage-level phylogeny (Figs. 1, 2) and the coalescent-based and concatenated phylogeny are largely concordant at the interspecific level 
(Fig. S2). The individual-level phylogeny exhibits high bootstrap support for the monophyly of all lineages but E. palmeri and E. asperifolia (Fig. 1). However, site-based and gene-level concordance (sCF and gCF) are low compared to bootstrap support (Fig. S3), which might be expected given the short internode distances in our phylogeny.

Both our lineage-level phylogenies were concordant (Fig. S4) and recovered three major clades (Fig. 2), two of which had been previously characterized as the californica and frutescens clades based on the species comprising the clades (Ehleringer \& Clark, 1988; Fehlberg \& Ranker, 2007). Additionally, we identified a third clade consisting of $E$. densifolia and E. ventorum. In contrast to previous phylogenetic studies for Encelia, statistical support for all nodes was uniformly high except for the placement of $E$. farinosa. The recent and rapid radiation in this group (Fig. 2) is also reflected in the low and relatively uniform levels of genetic divergence among lineages (average $F_{S T}=0.32, D_{x y}=0.024$, and $D_{a}=0.014$, Fig. S5).

Phylogenetic networks inferred by SNAQ strongly supported one hybridization edge between $E$. californica 2 and $E$. asperifolia, with admixture proportions of 0.49 and 0.51 between the two species (Fig. S6). Our D-statistic results identified multiple, strongly supported examples of introgression among lineages (Fig. S7; Table S3), including lineages that are known to hybridize in nature (e.g., E. actoni and E. frutescens; Fig. 3; Table S4).

\section{Comparative analyses}

Using the crown age estimator across a range of extinction rates and our time-calibrated phylogeny (Fig. 2), we found rates of diversification in Encelia vary from $1.57(\varepsilon=0.1), 1.52(\varepsilon=$ $0.3)$, to 0.66 species per million years $(\mathrm{Myr})(\varepsilon=0.9)$ depending on the extinction scenario.

Reconstruction of trait evolution showed that closely-related species often have divergent trait values in nearly all phenotypes measured, indicative of widespread phenotypic divergence among Encelia species (Figs. 4, S8). This pattern of trait divergence is reflected in both low phylogenetic signal across all traits tested except leaf area (average lambda $=0.19$, range $=0$ to 1.16 , Table 1 ) and rapid trait evolution (average felsens $=0.98$, range $=0.02$ to 6.23 , Table 1). Rapid evolution in traits is mirrored by rapid transitions in environmental space in Encelia. Both within and among species and clades, a wide diversity of climatic space is occupied (Figs. S8, S9) and closely-related species often occupy very distinct climatic spaces (Figs. 4, S8). For 
example, individual species or clades can occupy temperatures from below freezing to $>40^{\circ} \mathrm{C}$ or rainfall from close to $0 \mathrm{~mm}$ to $200 \mathrm{~mm}$ (Fig. S9).

Disparity-through-time (DTT) patterns fell within expectations under random Brownian evolution (Fig. S10). Across traits, correlations between traits were generally weak, and only a few trait combinations were significant (Fig. S11). Further, very few of the comparisons between traits and environmental variables were significant (Fig. S12), even though most correlations followed general physiological predictions (Table S5).

The ancestral range reconstruction under DEC in BioGeoBears returned fairly uncertain inference at deeper nodes. However, these results confirmed the origins of Encelia in some combination of the hot deserts (e.g., the Sonoran, Baja and Mojave Deserts; Fig. S1).

Following expectations, overlapping species-pairs showed greater similarity in climatic and soil envelopes than non-overlapping pairs (Fig. 5). However, many species that occupied the same environmental space -- including those that overlapped in geographic range -- differed as much in morphology as species pairs in completely different environmental spaces.

\section{Discussion}

Encelia is an enigmatic but charismatic group that has been a model system for ecophysiological studies of desert plants (Ehleringer et al., 1981; Ehleringer, 1988; Ehleringer \& Cook, 1990; Ehleringer \& Sandquist, 2018). Previous phylogenetic studies based on both molecular and phenotypic data have failed to infer a well-resolved phylogeny of these plants because Encelia is a recent, rapid radiation and because of frequent hybridization (Fehlberg \& Ranker, 2007). Aided by a phylogenomic dataset and extensive taxon sampling, we disentangled this radiation and resolved the evolutionary relationships among all sampled species (Fig. 2). In particular, we inferred the relationships between and within two previously identified clades: the frutescens clade, which includes the species found in the cold deserts of North America (E. actoni, E. virginensis, E. resinifera, E. frutescens, and E. ravenii), and the californica clade, which includes the majority of the diversity found in Baja California ( $E$. farinosa, E. canescens, E. palmeri, E. asperifolia, and E. californica). Further, we found support for a new clade including $E$. densifolia and $E$. ventorum, both species restricted to Baja 
California. Together, these results suggest a pattern of phylogenetic eco-geographic structure whereby closely related species are largely restricted to the same or adjacent ecogeographic region (Figs. 1, S1).

\section{Rapid recent diversification and disparification in Encelia}

Encelia has diversified recently and rapidly (Fig. 2), with 0.9 - 1.57 species produced per million years (Myr). In comparison, Hawaiian silverswords radiated at 0.56 species per Myr (Baldwin \& Sanderson, 1998), Southern African ice plants at 0.77 - 1.75 species per Myr (Klak et al., 2004), and New World Lupinus at 2.49 - 3.79 species per Myr (Hughes \& Eastwood, 2006). Further, the two genera most closely related to Encelia (Enceliopsis and Gerea) are both relatively species-poor (four and two species, respectively), have older crown ages (Smith \& Brown, 2018), and, accordingly, have much lower diversification rates. Thus, both within its local phylogenetic context and compared to other plant groups, Encelia has relatively high rates of diversification.

Concomitant with rapid diversification, Encelia shows rapid disparification. The absolute range of phenotypes seen within Encelia are broad even between closely related species, with leaf area varying 10 -fold and trichome density varying $>1000$-fold (Figs. $4, \mathrm{~S} 8$ ). While this range is narrow relative to the full diversity seen in angiosperms (Wright et al., 2004), it is striking given the young age of Encelia. Accordingly, Encelia has rates of trait evolution comparable to notable adaptive radiations. For example, leaf size evolves at an estimated 0.49 felsens compared to 0.46 in lobeliads and 2.08 in silverswords (Table 1, Ackerly, 2009). Unfortunately, we lack comparative data from other plant radiations for many of the traits we measured in Encelia. However, our estimated rates of evolution for other traits are high, exhibiting felsens $>5$ for trichome density, even without accounting for the multiple types of trichomes that occur among Encelia (Fig. 2; Ehleringer \& Cook, 1987).

Although closely related species diverge extensively in phenotype, distantly related species often share similar phenotypes (e.g., E. farinosa farinosa and E. ravenii in trichome density, Fig. 4). This pattern of low phylogenetic signal suggests that accessibility to adaptive traits has enabled Encelia to diversify across a mosaic of environmental conditions and adaptive optima. Along with rapid trait evolution, Encelia species exhibit transitions along climate and soil gradients (Fig. 4, S8, S9), suggesting that Encelia species are capable of rapidly adapting to 
novel environmental conditions. Taken together, our findings suggest that high tait lability and rapid trait evolution are key syndromes underpinning the evolvability of the Encelia radiation.

\section{Drivers of diversification and disparification in Encelia}

Encelia represents an excellent system for testing hypotheses for why deserts can generate exceptional diversity. First, the recent formation of arid habitats has provided new habitats in which desert-adapted species can diversify (Mooney \& Zavaleta, 2016). Indeed, though reconstruction of Encelia's ancestry ranges was inconclusive, it suggested Encelia most likely originated in the hot deserts, from which the frutescens clade spread into the cold deserts around $\sim 0.5$ myr (Fig. S1). Outside of the two species (E. canescens and E. hispida) that colonized Peru and the Galapagos Islands, the center of biodiversity of Encelia is in the deserts of North America. These deserts have changed through time and across space over the last 5 million years, with their initial formation and subsequent volcanic eruptions that likely eradicated much of the living flora (Conly et al., 2005; Garrick et al., 2009), sea incursions that divided the peninsula into isolated landmasses (Holt et al., 2000; Riddle et al., 2000), tectonic movement that led to the creation of the Baja peninsula (Dolby et al., 2015), and glacial climate cycles that affected sea levels and habitat distributions (Van Devender \& Spaulding, 1979; Thompson \& Anderson, 2000). Although many phylogeographic studies place these landscape changes in the Pliocene, their timing is uncertain and certainly could have influenced the diversification of Encelia (Wilson \& Pitts, 2010). These changes both allowed colonization of new habitats and divided existing populations, resulting in population isolation that would lead to increased diversification. Indeed, the population structure of multiple animal and plant species in the North American deserts (Riddle et al., 2000; Crews \& Hedin, 2006; Garrick et al., 2009) reflects this history, most notably with splits across northern and southern Baja California and across the Sonoran and Baja Californian deserts. Encelia also presents evidence of this geographic pattern; of the five species that occur on the Baja peninsula, four of them (E. densifolia, $E$. palmeri, E. ventorum and E. asperifolia; Fig. 1) are restricted to the southern portion of the peninsula.

Second, although deserts are often characterized as homogenous swaths of arid land, deserts span large and often steep topological and environmental gradients, which can drive divergent selection and ecological speciation. Although all Encelia species are concentrated in North American deserts, they span multiple such gradients. Encelia species live in a diversity of 
climatic niches, experiencing hottest month temperatures ranging from 25 to $40^{\circ} \mathrm{C}$, coldest month temperatures ranging from -5 to $8^{\circ} \mathrm{C}$, and driest months ranging from 0 to 5 inches of rain (Figs. 4, S8). Although some of these absolute differences are small, they can represent large relative differences when resources are so limited. Notably, a few species are climatic outliers such as E. californica, which lives along the California coast, experiences high rainfall (Fig. S8, S9), and E. actoni, E. resinifera, and E. virginensis which all survive freezing temperatures (Fig. 4, S9). This climatic variance exemplifies the types of gradients that Encelia spans and that can drive diversification and disparification. Unlike species in many rapid radiations (Givnish, 1997), Encelia species are rarely sympatric and instead tend to share parapatric boundaries, defined by local environmental and edaphic transitions. Although contemporary geographic distributions do not necessarily reflect historical distributions, this pattern of species turnover across environmental gradients suggests that spatial environmental heterogeneity might have driven Encelia speciation.

Third, in arid habitats, multiple environmental gradients can interact and overlap at different spatial scales. Many Encelia species have parapatric geographic ranges (Fig. 1) and thus experience very similar climatic conditions (e.g., similar rainfall and solar insolation; Fig. 5). However, many of these species pairs are segregated along strong environmental gradients that occur over just a few meters, leading to marked phenotypic differences. Furthermore, the possible anatomical, physiological, and phenological adaptations to living in the stressful and resource-limited conditions of deserts are numerous, and combinations of these adaptive traits may all be equally fit, resulting in both high disparification and diversity (Stebbins, 1952; Roddy et al., 2020). For example, E. ventorum occurs in sandy dunes that face the ocean, which encroach upon the inland deserts where E. palmeri is found (Kyhos et al., 1981; DiVittorio et al., 2020). E. ventorum can access the water table below the dunes but is also constantly exposed to osmotic stress from ocean spray. Thus, although these two species occur adjacent to each other and experience similar climates, they experience different levels of water availability and salt stress as well as different soil types, factors that together drive their phenotypic divergence in trichome density, leaf size, and shoot hydraulics (Fig. 2, 4). Similarly, E. frutescens and E. farinosa both occur in Death Valley, one of the hottest places in North America. E. farinosa has large leaves with abundant trichomes, while $E$. frutescens has small leaves with few trichomes (Fig. 4). These differences in leaf morphology influence their microhabitat occupations. $E$. frutescens occurs in wash habitats with higher water availability and uses transpirational cooling 
from its small leaves to maintain low leaf temperatures. In turn, E. farinosa occurs along dry slopes where its trichomes reflect solar radiation to maintain low leaf temperatures (Ehleringer, 1988). The same relationships between trichome density, leaf size, and water access also seem to influence microhabitat occupation by E. palmeri and E. ventorum (DiVittorio et al., 2020). These traits might have evolved repeatedly throughout Encelia in relation to fine-scale environmental heterogeneity.

These case studies exemplify how no single trait may be responsible for driving the radiation of Encelia. Rather, the high lability of multiple traits with compensatory physiological and fitness effects may have driven rapid trait evolution in Encelia, resulting in heightened diversification. As seen in other plant clades, trait lability could be a critical organismal syndrome to evolutionarily accessible phenotypes, which enables diversification within and across environments (Ogburn et al., 2015). Writ large, trait lability would explain the lack of clear correlations between traits and broad-scale environmental conditions in Encelia (Fig. S12), weak correlations among traits (Fig. S11), and the presence of geographically-overlapping species that differ dramatically in morphology (Fig. 5). The diversity of traits associated with desert survival in Encelia exemplifies how aridity can be a catalyst of diversification and disparification.

\section{Hybridization and introgression and the Encelia radiation}

In addition to biogeographic and environmental factors, hybridization and introgression have both contributed to the rapid diversification and disparification of Encelia and served as a source of genetic variation and for new species (Anderson \& Stebbins, 1954; Stebbins, 1959; Marques et al., 2019). Using two complementary approaches, we found numerous examples of introgression across Encelia, including across non-sister species and species in different major clades (Figs. S6, S7). In many cases, the instances of introgression are corroborated by field data of naturally occurring hybrids and by cases of suspected hybrid speciation (Fig. 3). Rampant hybridization has now been uncovered in multiple rapid radiations, such as the Hawaiian silversword alliance (Barrier et al., 1999), African cichlids (Meier et al., 2017), and Heliconius butterflies (Edelman et al., 2019). To this list, we can now add Encelia.

Several aspects of Encelia biology and geography likely enabled this history of hybridization and introgression. Encelia species exhibit few of the barriers that restrict gene flow in other species: 
all species except E. canescens and likely E. hispida are obligate outcrossers, chromosome number is conserved across the genus, the species are pollinated by generalist pollinators, and, at the regional scale, they have only modest differences in flowering phenology (Ehleringer \& Clark, 1988; Clark, 1998). Further, many Encelia species ranges are adjacent to each other (Fig. 1), across which dispersal is more permissible than barriers like mountains. Lastly, in the cold deserts, which are home to a number of species in the frutescens clade, midden data suggest that repeated glacial cycles led to repeated range retractions to relictual populations followed by range expansions (Spaulding \& Graumlich, 1986; Thompson \& Anderson, 2000). These recurrent bouts of secondary contact could drive introgression between species (Fehlberg \& Ranker, 2009; Hewitt, 2011; Folk et al., 2018), as outlined in the species-pump hypothesis (Papadopoulou \& Knowles, 2015).

This history of hybridization and introgression might promote diversification by helping originate hybrid species. Previous studies of Encelia identified four putative cases of hybrid species (Table S4, Fig. 3): E. actoni $x$ E. frutescens to result in both $E$. virginensis and E. resinifera, $E$. californica $x$ E. frutescens to result in E. asperifolia, and E. farinosa $x$ E. palmeri to result in $E$. canescens (Clark \& Allan, 1997; Allan et al., 1997; Clark, 1998). In each of these four cases, our D-statistic and SNAQ results confirm introgression edges either between the parental species or between the parental species and the putative hybrid species. Most notably, the admixture edge from $E$. californica to $E$. asperifolia was estimated at approximately $50 \%$, as would be expected in hybrid speciation (Fig. S6). Confirming these cases of hybrid speciation will require more detailed analyses of the genome and spatial structure of these parental and putative hybrid species. Yet, these results provide compelling evidence that diversification in Encelia is partially driven by hybrid speciation.

Introgression can also help spur radiations by increasing the amount of genetic variation in a species (Suarez-Gonzalez et al., 2018). Genetic variation can arise from a few sources: de novo mutations, standing genetic variation, and gene flow between populations or species. Typically, de novo mutations are thought unlikely to occur rapidly enough to drive rapid divergence (Barrett \& Schluter, 2008). In contrast, both standing genetic variation and gene flow can provide an influx of variation to diverging populations (Hedrick, 2013; Suarez-Gonzalez et al., 2018), allowing them to quickly adapt to new ecological conditions. In either case, distantly related species would exhibit similar phenotypes (Lee \& Coop, 2019; Jamie \& Meier, 2020), as 
occurs in Encelia (Fig. 4, S8). As yet, it is unclear if shared traits in Encelia arose from differential sorting of ancestral variation, introgression, or true convergent evolution. Reconstructing this history will require identifying the loci underpinning the trait of interest and characterizing their specific histories (Giska et al., 2019).

Lastly, this history of introgression and hybridization in Encelia suggests that the genus might be a syngameon (Clark, 1998), a group of otherwise distinct species interconnected by gene exchange (Lotsy, 1925; Grant, 1971; Hipp et al., 2019). In this scenario, these species can be fully independent evolutionary lineages that retain their cohesiveness and distinctiveness despite hybridization. Species participating in the syngameon can persist as a consequence of reinforcement, assortative mating, divergent selection, or selection against hybrids (Cannon \& Petit, 2020). In particular, hybrid zone data suggest that extremely strong, divergent selection may be a predominant factor maintaining species boundaries in Encelia (DiVittorio et al., 2020). Given that geographically overlapping species often are quite phenotypically divergent (Fig. 5), divergent selection might be helping to maintain species cohesiveness throughout the genus.

\section{Conclusion}

Our integrative study within a single desert lineage provides new insights into the processes of plant evolution in one of the harshest terrestrial environments. The evolutionary history of Encelia provides an example of a radiation encompassing rapid and recent species formation, high phenotypic disparity, and strong ecological divergence - thus meeting many of the key requirements of an adaptive radiation (Givnish, 1997). Eco-phenotypic differentiation that results in functional and fitness tradeoffs are apparent across this radiation. Rather than homogenizing genetic lineages, interspecific gene flow increases genetic diversity within species and may facilitate adaptation. We suggest that the combined effects of high genetic diversity with high trait lability have enabled access to multiple adaptive peaks, leading to species diversification and disparification across steep environmental gradients both at broad and fine spatial scales. Much remains to be learned about the mechanisms underpinning this radiation. The patchy environmental heterogeneity characteristic of the deserts presents an exciting opportunity to model explicitly the influence of a complex fitness landscape with multiple optima on the genomic background of a radiating lineage (Martin \& Richards, 2019). The extent to which 
interspecific gene flow has enabled adaptation in this scenario is a critical area for continued study.

\section{Acknowledgements}

We acknowledge funding from UC Mexus to CD \& SS, from a NSF Postdoctoral Fellowship in Biology to SS (DEB-1519732), a CSUDH Norris Faculty Grant to SS, and by a postdoctoral fellowship from the Yale Institute for Biospheric Studies to ABR. We thank the UC Riverside AgOps team for their efforts in maintaining the common garden and Danny Eduardo Carvajal López and Darren Sandquist for providing seeds for E. canescens. Comments from I. Holmes improved a previous version of this manuscript. MicroCT imaging was performed at the Lawrence Berkeley National Laboratory Advanced Light Source Beamline 8.3.2 microtomography facility, with help from D. Parkinson and A. MacDowell. The Advanced Light Source is supported by the Director, Office of Science, Office of Basic Energy Services, of the U.S. Department of Energy under contract no. DE-AC01-05CH11231.

\section{Author Contributions}

SS, ABR, FZ designed the research. SS, ABR, CD, CLH, CRB, ASA, and FZ conducted the research. SS, ABR, and $F Z$ analyzed and interpreted data. SS, ABR, and FZ wrote the manuscript.

\section{Data Availability}

Raw sequence data are available at SRA <accession numberTBD>. Alignments and variant call sets used in population genetic and phylogenetic inference are available on DataDryad <DOI TBD>. Trait measurements are available on DataDryad <DOI TBD>. All scripts used to analyze and visualize data are available on GitHub <link TBD>.

\section{References}

Ackerly D. 2009. Conservatism and diversification of plant functional traits: evolutionary rates versus phylogenetic signal. Proceedings of the National Academy of Sciences 106 Suppl 2: 19699-19706. 
Aiello-Lammens ME, Boria RA, Radosavljevic A, Vilela B, Anderson RP. 2015. spThin: an $\mathrm{R}$ package for spatial thinning of species occurrence records for use in ecological niche models. Ecography 38: 541-545.

Allan GJ, Clark C, Rieseberg LH. 1997. Distribution of parental DNA markers in Encelia virginensis (Asteraceae: Heliantheae), a diploid species of putative hybrid origin. Plant systematics and evolution 205: 205-221.

Anderson E, Stebbins GL. 1954. Hybridization as an evolutionary stimulus. Evolution 8: 378-388.

Arakaki M, Christin P-A, Nyffeler R, Lendel A, Eggli U, Ogburn RM, Spriggs E, Moore MJ, Edwards EJ. 2011. Contemporaneous and recent radiations of the world's major succulent plant lineages. Proceedings of the National Academy of Sciences 108: 8379-8384.

Axelrod DI. 1972. Edaphic aridity as a factor in angiosperm evolution. The American Naturalist 106: 311-320.

Baldwin BG, Sanderson MJ. 1998. Age and rate of diversification of the Hawaiian silversword alliance (Compositae). Proceedings of the National Academy of Sciences of the United States of America 95: 9402-9406.

Barrett RDH, Schluter D. 2008. Adaptation from standing genetic variation. Trends in Ecology \& Evolution 23: 38-44.

Barrier M, Baldwin BG, Robichaux RH, Purugganan MD. 1999. Interspecific hybrid ancestry of a plant adaptive radiation: allopolyploidy of the Hawaiian silversword alliance (Asteraceae) inferred from floral homeotic gene duplications. Molecular Biology and Evolution 16: 1105-1113.

Bivand R, Rundel C. 2017. rgeos: interface to geometry engine-open source (GEOS). $R$ package version 0. 3-26.

Bolger AM, Lohse M, Usadel B. 2014. Trimmomatic: a flexible trimmer for Illumina sequence data. Bioinformatics 30: 2114-2120.

Brodersen CR. 2013. Visualizing wood anatomy in three dimensions with high-resolution X-ray 
micro-tomography $(\mu \mathrm{CT})$ - a review. IAWA Journal 34: 408-424.

Brodersen CR, Roddy AB. 2016. New frontiers in the three-dimensional visualization of plant structure and function. American journal of botany 103: 184-188.

Cannon CH, Petit RJ. 2020. The oak syngameon: more than the sum of its parts. The New Phytologist 226: 978-983.

Chifman J, Kubatko L. 2014. Quartet inference from SNP data under the coalescent model. Bioinformatics 30: 3317-3324.

Clark C. 1998. Phylogeny and Adaptation in the Encelia Alliance (Asteraceae: Helliantheae). Aliso: A Journal of Systematic and Evolutionary Botany 17: 89-98.

Clark C, Allan GJ. 1997. Hybrid speciation with external barriers: Encelia (Asteraceae: Heliantheae), a case study. American Journal of Botany 83: 249.

Conly AG, Brenan JM, Bellon H, Scott SD. 2005. Arc to rift transitional volcanism in the Santa Rosalia region, Baja California Sur, Mexico. Journal of Volcanology and Geothermal Research 142: 303-341.

Crews SC, Hedin M. 2006. Studies of morphological and molecular phylogenetic divergence in spiders (Araneae: Homalonychus) from the American southwest, including divergence along the Baja California Peninsula. Molecular Phylogenetics and Evolution 38: 470-487.

Cummings MP, Handley SA, Myers DS, Reed DL, Rokas A, Winka K. 2003. Comparing bootstrap and posterior probability values in the four-taxon case. Systematic biology $\mathbf{5 2 :}$ 477-487.

DiVittorio CD, Singhal S, Roddy AB, Zapata F, Ackerly DD, Baldwin BG, Brodersen CR, Burquez A, Fine PVA, Flores MP, et al. 2020. Natural selection maintains species despite widespread hybridization in the desert shrub Encelia. bioRxiv: 2020.01.23.917021.

Dolby GA, Bennett SEK, Lira-Noriega A, Wilder BT, Munguía-Vega A. 2015. Assessing the geological and climatic forcing of biodiversity and evolution surrounding the Gulf of California. Journal of the Southwest 57: 391-455. 
Durand EY, Patterson N, Reich D, Slatkin M. 2011. Testing for ancient admixture between closely related populations. Molecular Biology and Evolution 28: 2239-2252.

Eaton DAR, Ree RH. 2013. Inferring phylogeny and introgression using RADseq data: an example from flowering plants (Pedicularis: Orobanchaceae). Systematic Biology 62: 689-706.

Edelman NB, Frandsen PB, Miyagi M, Clavijo B, Davey J, Dikow R, García-Accinelli G, van Belleghem S, Patterson N, Neafsey DE, et al. 2019. Genomic architecture and introgression shape a butterfly radiation. Science 366: 594-599.

Ehleringer JR. 1988. Comparative ecophysiology of Encelia farinosa and Encelia frutescens. Oecologia 76: 553-561.

Ehleringer JR, Clark C. 1988. Evolution and adaptation in Encelia (Asteraceae). Plant Evolutionary Biology: 221-248.

Ehleringer JR, Cook CS. 1987. Leaf hairs in Encelia (Asteraceae). American Journal of Botany 74: 1532-1540.

Ehleringer JR, Cook CS. 1990. Characteristics of Encelia species differing in leaf reflectance and transpiration rate under common garden conditions. Oecologia 82: 484-489.

Ehleringer J, Mooney HA, Gulmon SL, Rundel PW. 1981. Parallel evolution of leaf pubescence in Encelia in coastal deserts of North and South America. Oecologia 49: 38-41.

Ehleringer JR, Sandquist DR. 2018. A tale of ENSO, PDO, and increasing aridity impacts on drought-deciduous shrubs in the Death Valley region. Oecologia 187: 879-895.

Ellis AG, Weis AE, Gaut BS. 2006. Evolutionary radiation of 'stone plants' in the genus Argyroderma (Aizoaceae): unraveling the effects of landscape, habitat, and flowering time. Evolution 60: 39.

Fehlberg SD, Fehlberg KM. 2017. Spatial genetic structure in brittlebush (Encelia farinosa, Asteraceae) in the southwestern deserts of North America: a comparison of nuclear and chloroplast DNA sequences. Plant Systematics and Evolution 303: 1367-1382.

Fehlberg SD, Ranker TA. 2007. Phylogeny and biogeography of Encelia (Asteraceae) in the 
Sonoran and Peninsular deserts based on multiple DNA sequences. Systematic botany 32: 692-699.

Fehlberg SD, Ranker TA. 2009. Evolutionary history and phylogeography of Encelia farinosa (Asteraceae) from the Sonoran, Mojave, and Peninsular Deserts. Molecular Phylogenetics and Evolution 50: 326-335.

Fick SE, Hijmans RJ. 2017. WorldClim 2: new 1-km spatial resolution climate surfaces for global land areas. International Journal of Climatology 37: 4302-4315.

Folk RA, Soltis PS, Soltis DE, Guralnick R. 2018. New prospects in the detection and comparative analysis of hybridization in the tree of life. American Journal of Botany 105: 364-375.

Garrick RC, Nason JD, Meadows CA, Dyer RJ. 2009. Not just vicariance: phylogeography of a Sonoran Desert euphorb indicates a major role of range expansion along the Baja peninsula. Molecular Ecology 18: 1916-1931.

GBIF. 2019. GBIF Occurrence Download for Encelia.

Giska I, Farelo L, Pimenta J, Seixas FA, Ferreira MS, Marques JP, Miranda I, Letty J, Jenny H, Hackländer K, et al. 2019. Introgression drives repeated evolution of winter coat color polymorphism in hares. Proceedings of the National Academy of Sciences of the United States of America 116: 24150-24156.

Givnish TJ. 1997. Adaptive radiation and molecular systematics: issues and approaches. Molecular evolution and adaptive radiation: 1-54.

Grant V. 1971. Plant Speciation. Columbia University Press.

Harmon LJ, Schulte JA, Larson A, Losos JB. 2003. Tempo and mode of evolutionary radiation in iguanian lizards. Science 301: 961-964.

Harmon LJ, Weir JT, Brock CD, Glor RE, Challenger W. 2008. GEIGER: investigating evolutionary radiations. Bioinformatics 24: 129-131.

Hedrick PW. 2013. Adaptive introgression in animals: examples and comparison to new 
mutation and standing variation as sources of adaptive variation. Molecular Ecology 22: 4606-4618.

Hernández-Hernández T, Brown JW, Schlumpberger BO, Eguiarte LE, Magallón S. 2014. Beyond aridification: multiple explanations for the elevated diversification of cacti in the New World Succulent Biome. The New Phytologist 202: 1382-1397.

Hernandez-Hernandez T, Hernandez HM, De-Nova JA, Puente R, Eguiarte LE, Magallon S. 2011. Phylogenetic relationships and evolution of growth form in Cactaceae (Caryophyllales, Eudicotyledoneae). American journal of botany 98: 44-61.

Hewitt GM. 2011. Quaternary phylogeography: the roots of hybrid zones. Genetica 139: 617-638.

Hijmans RJ, Van Etten J, Cheng J, Mattiuzzi M, Sumner M, Greenberg JA, Lamigueiro OP, Bevan A, Racine EB, Shortridge A, et al. 2015. Package 'raster'. R package 734.

Hipp AL, Whittemore AT, Garner M, Hahn M, Fitzek E, Guichoux E, Cavender-Bares J, Gugger PF, Manos PS, Pearse IS, et al. 2019. Genomic identity of white oak species in an eastern North American syngameon. Annals of the Missouri Botanical Garden. Missouri Botanical Garden 104: 455-477.

Holt JW, Holt EW, Stock JM. 2000. An age constraint on Gulf of California rifting from the Santa Rosalía basin, Baja California Sur, Mexico. Geological Society of America Bulletin 112: 540-549.

Hughes C, Eastwood R. 2006. Island radiation on a continental scale: exceptional rates of plant diversification after uplift of the Andes. Proceedings of the National Academy of Sciences of the United States of America 103: 10334-10339.

Jamie GA, Meier JI. 2020. The persistence of polymorphisms across species radiations. Trends in Ecology \& Evolution in press.

Katoh K, Asimenos G, Toh H. 2009. Multiple alignment of DNA sequences with MAFFT. Methods in Molecular Biology 537: 39-64.

Klak C, Reeves G, Hedderson T. 2004. Unmatched tempo of evolution in Southern African 
semi-desert ice plants. Nature 427: 63-65.

Kolb KJ, Sperry JS, Lamont BB. 1996. A method for measuring xylem hydraulic conductance and embolism in entire root and shoot systems. Journal of Experimental Botany 47: 1805-1810.

Kyhos DW. 1967. Natural hybridization between Encelia and Geraea (Compositae) and some related experimental investigations. Madroño 19: 33-43.

Kyhos DW, Clark C, Thompson WC. 1981. The hybrid nature of Encelia laciniata (Compositae: Heliantheae) and control of population composition by post-dispersal selection. Systematic Botany 6: 399-411.

Lee KM, Coop G. 2019. Population genomics perspectives on convergent adaptation. Philosophical Transactions of the Royal Society of London. 374: 20180236.

Li H. 2013. Aligning sequence reads, clone sequences and assembly contigs with BWA-MEM. arXiv [q-bio.GN].

Li H, Handsaker B, Wysoker A, Fennell T, Ruan J, Homer N, Marth G, Abecasis G, Durbin R, 1000 Genome Project Data Processing Subgroup. 2009. The Sequence Alignment/Map format and SAMtools. Bioinformatics 25: 2078-2079.

Liu S, Wei Y, Post WM, Cook RB, Schaefer K, Thornton MM. 2014. NACP MsTMIP: Unified North American Soil Map. ORNL DAAC.

Lotsy JP. 1925. Species or linneon. Genetica 7: 487-506.

Magallón S, Gómez-Acevedo S, Sánchez-Reyes LL, Hernández-Hernández T. 2015. A metacalibrated time-tree documents the early rise of flowering plant phylogenetic diversity. The New Phytologist 207: 437-453.

Magallón S, Sanderson MJ. 2001. Absolute diversification rates in angiosperm clades. Evolution 55: 1762-1780.

Malinsky M, Svardal H, Tyers AM, Miska EA, Genner MJ, Turner GF, Durbin R. 2018. Whole-genome sequences of Malawi cichlids reveal multiple radiations interconnected by gene flow. Nature Ecology \& Evolution 2: 1940-1955. 
Marques DA, Meier JI, Seehausen O. 2019. A combinatorial view on speciation and adaptive radiation. Trends in Ecology \& Evolution 34: 531-544.

Martin CH, Richards EJ. 2019. The paradox behind the pattern of rapid adaptive radiation: how can the speciation process sustain itself through an early burst? Annual Review of Ecology, Evolution, and Systematics 50: 569-593.

Matzke NJ. 2013. Probabilistic historical biogeography: new models for founder-event speciation, imperfect detection, and fossils allow improved accuracy and model-testing. Frontiers of Biogeography 5: 242-248.

Meier JI, Marques DA, Mwaiko S, Wagner CE, Excoffier L, Seehausen O. 2017. Ancient hybridization fuels rapid cichlid fish adaptive radiations. Nature Communications 8: 14363.

Minh BQ, Hahn MW, Lanfear R. 2020. New methods to calculate concordance factors for phylogenomic datasets. Molecular Biology and Evolution in press.

Mooney H, Zavaleta E. 2016. Ecosystems of California. Univ of California Press.

Nei M. 1978. Estimation of average heterozygosity and genetic distance from a small number of individuals. Genetics 89: 583-590.

Niklas KJ. 1994. Morphological evolution through complex domains of fitness. Proceedings of the National Academy of Sciences 91: 6772-6779.

Ogburn RM, Matthew Ogburn R, Edwards EJ. 2015. Life history lability underlies rapid climate niche evolution in the angiosperm clade Montiaceae. Molecular Phylogenetics and Evolution 92: 181-192.

Omernik JM, Griffith GE. 2014. Ecoregions of the conterminous United States: evolution of a hierarchical spatial framework. Environmental Management 54: 1249-1266.

Oskin M, Stock J. 2003. Marine incursion synchronous with plate-boundary localization in the Gulf of California. Geology 31: 23-26.

Pagel M. 1999. Inferring the historical patterns of biological evolution. Nature 401: 877-884.

Papadopoulou A, Knowles LL. 2015. Genomic tests of the species-pump hypothesis: recent 
island connectivity cycles drive population divergence but not speciation in Caribbean crickets across the .... Evolution 69: 1501-1517.

Paradis E, Claude J, Strimmer K. 2004. APE: Analyses of Phylogenetics and Evolution in R language. Bioinformatics 20: 289-290.

Pateiro López B, Rodríguez Casal A. 2010. Generalizing the convex hull of a sample: the R package alphahull. Journal of Statistical Software 34: 1-28.

Peterson BK, Weber JN, Kay EH, Fisher HS, Hoekstra HE. 2012. Double digest RADseq: an inexpensive method for de novo SNP discovery and genotyping in model and non-model species. PloS one 7: e37135.

Pinheiro, J. 2009. nlme : Linear and nonlinear mixed effects models. R package version 3.1-96. http://cran.r-project.org/web/packages/nlme/.

Rasband WS, Others. 1997. ImageJ.

Ree RH, Sanmartín I. 2018. Conceptual and statistical problems with the DEC+J model of founder-event speciation and its comparison with DEC via model selection. Journal of Biogeography 45: 741-749.

Reich D, Thangaraj K, Patterson N, Price AL, Singh L. 2009. Reconstructing Indian population history. Nature 461: 489-494.

Revell LJ. 2012. phytools: an R package for phylogenetic comparative biology (and other things). Methods in Ecology and Evolution 3: 217-223.

Riddle BR, Hafner DJ, Alexander LF, Jaeger JR. 2000. Cryptic vicariance in the historical assembly of a Baja California peninsular desert biota. Proceedings of the National Academy of Sciences of the United States of America 97: 14438-14443.

Roddy AB, van Blerk JJ, Midgley JJ, West AG. 2019. Ramification has little impact on shoot hydraulic efficiency in the sexually dimorphic genus Leucadendron (Proteaceae). PeerJ 7: e6835.

Roddy AB, Brodersen CR, Dawson TE. 2016. Hydraulic conductance and the maintenance of 
water balance in flowers. Plant, Cell \& Environment 39: 2123-2132.

Roddy AB, Théroux-Rancourt G, Abbo T, Benedetti JW, Brodersen CR, Castro M, Castro S, Gilbride AB, Jensen B, Jiang G-F, et al. 2020. The scaling of genome size and cell size limits maximum rates of photosynthesis with implications for ecological strategies. International Journal of Plant Sciences.

Rognes T, Flouri T, Nichols B, Quince C, Mahé F. 2016. VSEARCH: a versatile open source tool for metagenomics. PeerJ 4: e2584.

Said Gutiérrez-Ortega J, Yamamoto T, Vovides AP, Angel Pérez-Farrera M, Martínez JF, Molina-Freaner F, Watano Y, Kajita T. 2018. Aridification as a driver of biodiversity: a case study for the cycad genus Dioon (Zamiaceae). Annals of Botany 121: 47-60.

Sandquist DR. 2014. Plants in Deserts. In: Monson RK, ed. Yearbook of the United States Department of Agriculture 1911. Ecology and the Environment. New York, NY: Springer New York, 297-326.

Sarver BAJ, Keeble S, Cosart T, Tucker PK, Dean MD, Good JM. 2017. Phylogenomic insights into mouse evolution using a pseudoreference approach. Genome Biology and Evolution 9: 726-739.

Smith SA, Brown JW. 2018. Constructing a broadly inclusive seed plant phylogeny. American Journal of Botany 105: 302-314.

Solís-Lemus C, Ané C. 2016. Inferring phylogenetic networks with maximum pseudolikelihood under incomplete lineage sorting (S Edwards, Ed.). PLOS Genetics 12: e1005896.

Sosa V, Vásquez-Cruz M, Villarreal-Quintanilla JA. 2020. Influence of climate stability on endemism of the vascular plants of the Chihuahuan Desert. Journal of Arid Environments 177: 104139.

Spaulding WG, Graumlich LJ. 1986. The last pluvial climatic episodes in the deserts of southwestern North America. Nature 320: 441-444.

Spotila JA, Farley KA, Sieh K. 1998. Uplift and erosion of the San Bernardino Mountains associated with transpression along the San Andreas fault, California, as constrained by 
radiogenic helium thermochronometry. Tectonics 17: 360-378.

Stamatakis A. 2014. RAxML version 8: a tool for phylogenetic analysis and post-analysis of large phylogenies. Bioinformatics 30: 1312-1313.

Stebbins GL. 1952. Aridity as a stimulus to plant evolution. The American Naturalist 86: 33-44.

Stebbins GL. 1959. The role of hybridization in evolution. Proceedings of the American Philosophical Society 103: 231-251.

Suarez-Gonzalez A, Lexer C, Cronk QCB. 2018. Adaptive introgression: a plant perspective. Biology letters 14: 20170688.

Thompson RS, Anderson KH. 2000. Biomes of western North America at 18,000, 6000 and 0 14C yr bp reconstructed from pollen and packrat midden data. Journal of Biogeography 27: $555-584$.

Van Devender TR, Spaulding WG. 1979. Development of vegetation and climate in the southwestern United States. Science 204: 701-710.

Wilson JS, Pitts JP. 2010. Illuminating the lack of consensus among descriptions of earth history data in the North American deserts: a resource for biologists. Progress in Physical Geography: Earth and Environment 34: 419-441.

Wright IJ, Reich PB, Westoby M, Ackerly DD, Baruch Z, Bongers F, Cavender-Bares J, Chapin T, Cornelissen JHC, Diemer M, et al. 2004. The worldwide leaf economics spectrum. Nature 428: 821-827.

Yu G, Smith DK, Zhu H, Guan Y, Lam TT. 2017. ggtree: an R package for visualization and annotation of phylogenetic trees with their covariates and other associated data (G Mclnerny, Ed.). Methods in Ecology and Evolution 8: 28-36.

Zerbino DR, Birney E. 2008. Velvet: algorithms for de novo short read assembly using de Bruijn graphs. Genome Research 18: 821-829.

Zhang J, Kobert K, Flouri T, Stamatakis A. 2014. PEAR: a fast and accurate Illumina Paired-End reAd mergeR. Bioinformatics 30: 614-620. 
Zhang C, Rabiee M, Sayyari E, Mirarab S. 2018. ASTRAL-III: polynomial time species tree reconstruction from partially resolved gene trees. BMC bioinformatics 19: 153.

Zizka A, Silvestro D, Andermann T, Azevedo J, Duarte Ritter C, Edler D, Farooq H, Herdean A, Ariza M, Scharn R, et al. 2019. CoordinateCleaner: standardized cleaning of occurrence records from biological collection databases. Methods in Ecology and Evolution 10: 744-751. 


\section{Details on Supplemental Information}

Expanded Methods: Expanded details on how genetic, trait, and spatial data were collected and analyzed in this study.

Figure S1: Ancestral range reconstruction in Encelia based on the DEC model implemented in BioGeoBEARS.

Figure S2: Individual-level phylogenies for Encelia inferred using a concatenated maximum-likelihood approach and a coalescent-based approach.

Figure S3: Nodal support for the individual-level phylogeny for Encelia as measured by bootstrap values and site and gene concordance factors.

Figure S4: Lineage-level phylogenies for Encelia inferred using a concatenated maximum-likelihood approach and a coalescent-based approach.

Figure S5: Genetic divergence between Encelia species, as measured by $\mathrm{F}_{\mathrm{ST}}, \mathrm{d}_{\mathrm{xy}}$, and $\mathrm{d}_{\mathrm{a}}$. Figure S6: Reconstruction of Encelia's evolutionary history as a network using SNaQ.

Figure S7: Introgression across Encelia as measured by the D-statistic.

Figure S8: Phenotypic variation in Encelia, depicted as phenograms.

Figure S9: The environmental space occupied by Encelia species across climatic variables.

Figure S10: Disparity-through-time plots for phenotypic variation in morphological traits and environmental space.

Figure S11: Pairwise correlations among all measured traits in Encelia.

Figure S12: Correlations between trait and environmental variables in Encelia.

Table S1: Detailed information on the 72 individuals included in this study, including their locality and species designations.

Table S2: The nine morphological and physiological traits measured in this study.

Table S3: Results of significant D-statistic tests for introgression.

Table S4: Instances of hybridization and introgression in the Encelia genus from both this study and previously-collected data.

Table S5: Expected correlations between traits and different environmental variables and the results recovered in this study. 


\section{Tables}

Table 1: Estimates of phylogenetic signal $(\lambda)$ and the associated significance and evolutionary rates (felsens; $\beta$ ) for each of the nine measured morphological and physiological traits.

$\begin{array}{ccccc}\text { traits } & \lambda & \mathrm{p} \text {-val } & \beta & \# \text { of tips } \\ \begin{array}{c}\text { canopy ramification } \\ \text { (BTSA) }\end{array} & 0 & 1 & 1.17 & 13 \\ \begin{array}{c}\text { Trichome density (top) } \\ \text { Stem hydraulic }\end{array} & 0 & 1 & 6.23 & 15 \\ \begin{array}{c}\text { conductance } \\ \text { Leaf color }\end{array} & 0.4 & 0.83 & 0.57 & 8 \\ \text { Leaf area } & 1.16 & 0.01 & 0.49 & 11 \\ \text { Leaf roundness } & 0 & 1 & 0.04 & 11 \\ \text { Leaf mass area (LMA) } & 0 & 1 & 0.18 & 11 \\ \text { Wood density } & 0 & 1 & 0.02 & 5 \\ \text { Vessel diameter } & 0 & 1 & 0.09 & 11\end{array}$




\section{Figures}

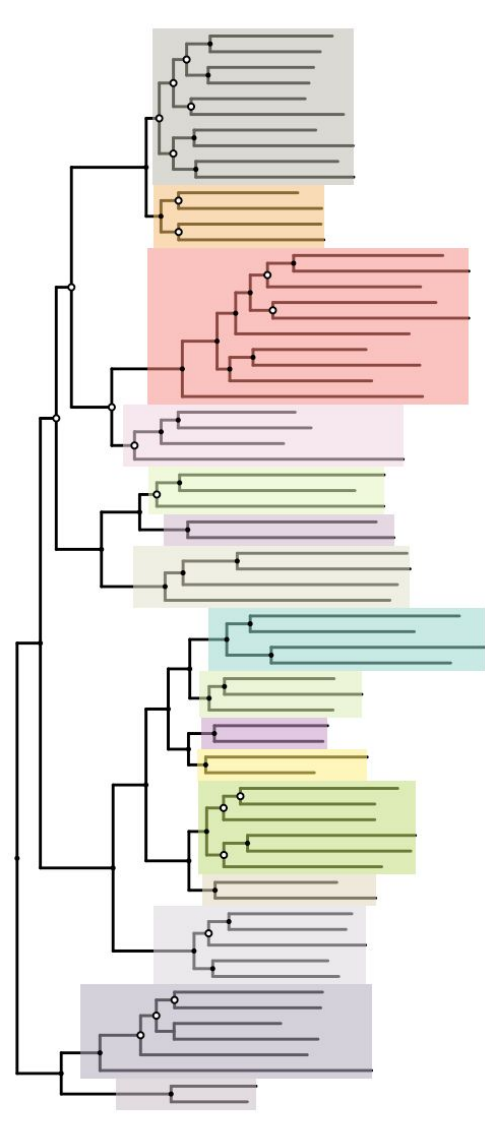

E. farinosa farinosa

E. farinosa phenicodonta

E. canescens

E. palmeri

E. asperifolia

E. californica2

E. californica1

E. actoni

E. virginensis1

E. resinifera

E. virginensis2

E. frutescens frutescens

E. frutescens glandulosa

E. ravenii

E. densifolia

E. ventorum
E. farinosa

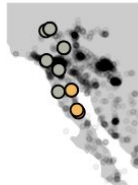

E. asperifolia

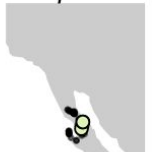

E. actoni

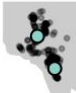

E. frutescens

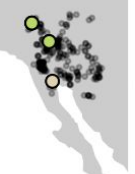

E. densifolia

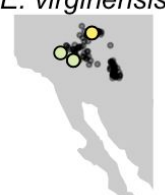

E. ravenii

E. californica
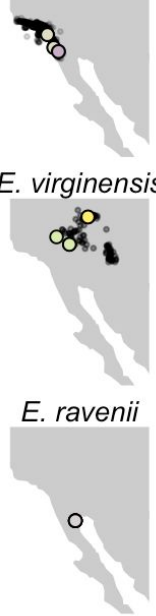

E. ventorum
E. resinifera

E. palmeri

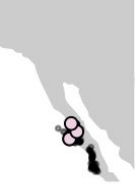

8\%:

Figure 1: Individual-level phylogeny of Encelia, inferred using RAXML on a concatenated alignment of $31 \mathrm{~K}$ loci. Shaded boxes demarcate clades; nodes with bootstrap $<95 \%$ are indicated in white. Maps show distribution of nominal species based on GBIF data as light gray points. Large filled points indicate sampling locations for individuals used in this study, colored by lineage identity. 

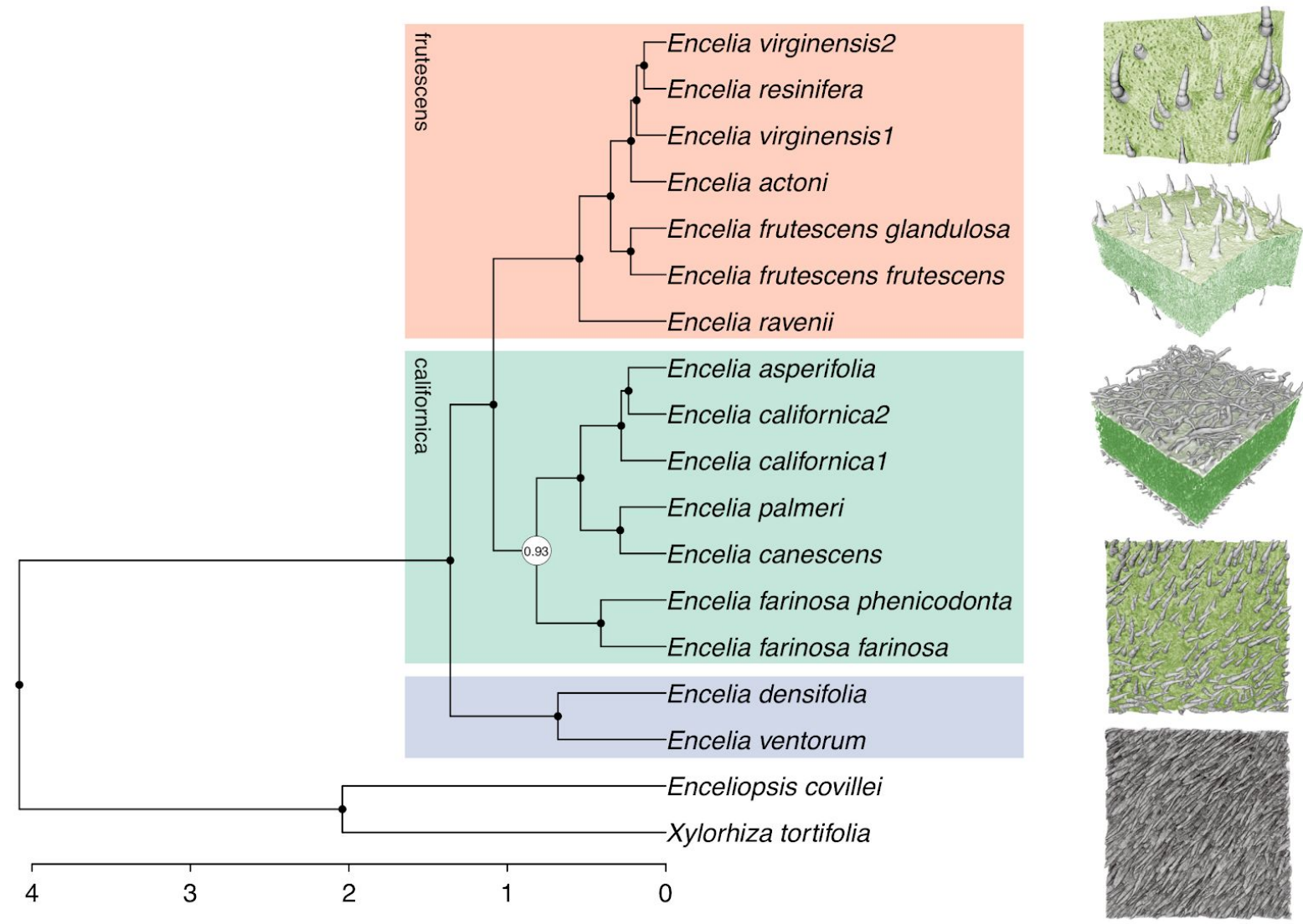

Figure 2: A lineage-level Encelia phylogeny inferred using the coalescent-based approach ASTRAL-III. MicroCT images show external leaf morphology of (top to bottom, with approximate widths of leading edges in parentheses): E. frutescens frutescens (950 $\mu \mathrm{m})$, E. asperifolia (550 $\mu \mathrm{m})$, E. palmeri $(650 \mu \mathrm{m})$, E. densifolia $(950 \mu \mathrm{m})$, and Enceliopsis covillei $(475 \mu \mathrm{m})$. Images were false-colored to indicate green, photosynthetic tissue and how trichomes alter leaf color. Boxes demarcate major clades; time scale shown in millions of years. Nodes with less than $95 \%$ local posterior probability shown in white. 


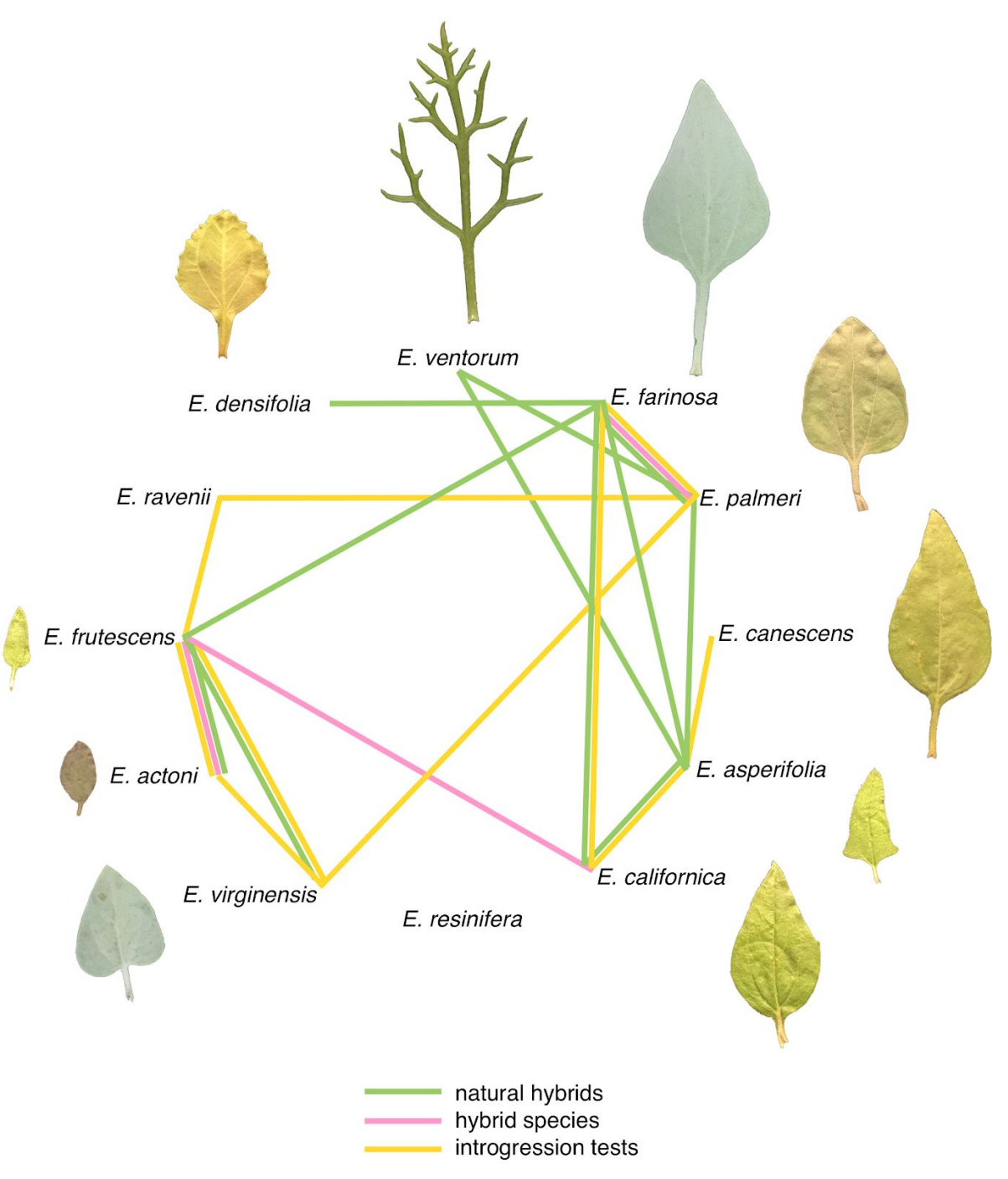

Figure 3: Hybridization and introgression in Encelia based on data from naturally-occurring hybrids, putative hybrid species, and tests of introgression (D-statistic \& SNaQ analyses; Fig. S6, Fig. S7, Table S4). Species are arranged by clade identity and leaf images are relative to size. Hybridization and introgression are rampant across the clade, and many of the species-pairs show evidence for hybridization and introgression across multiple measures of introgression. 


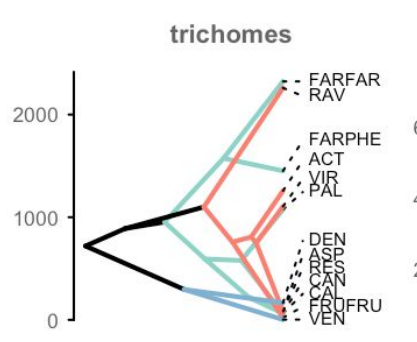

warmest temp.

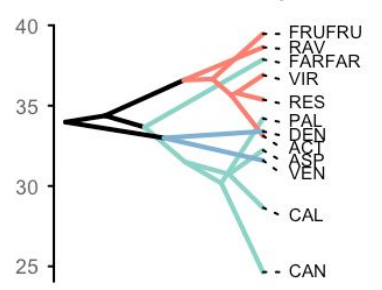

shoot hydr.

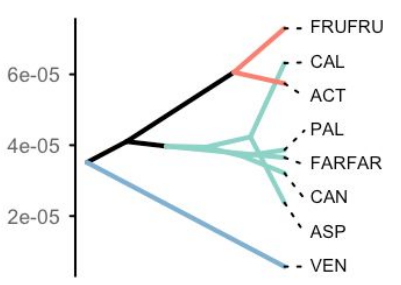

coldest temp.

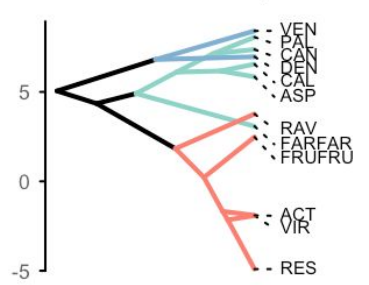

leaf area

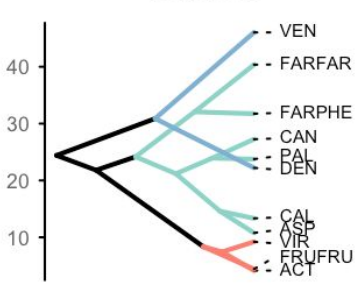

driest precip.

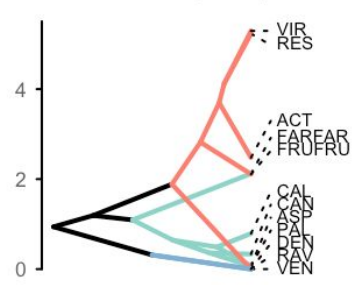

LMA

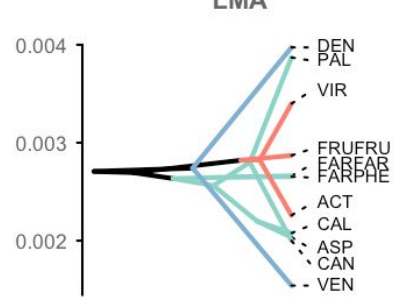

soil PC1

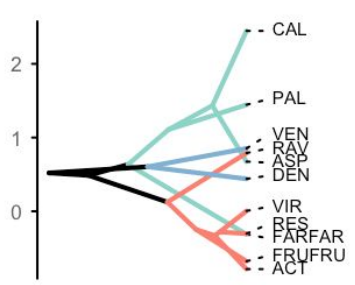

Figure 4: Phenotypic variation in Encelia, depicted as phenograms. The y-axis indicates phenotypic spread across (top) morphological and physiological traits and (bottom) environmental space. Abbreviations follow Table 1; all climatic variables are the extreme values across months. Branches are colored by clade identity as shown in Fig. 2, and all species names are abbreviated to the first three characters. Data for all traits and environmental measures shown in Fig. S8. Closely-related species in Encelia often exhibit dramatically different phenotypes. 

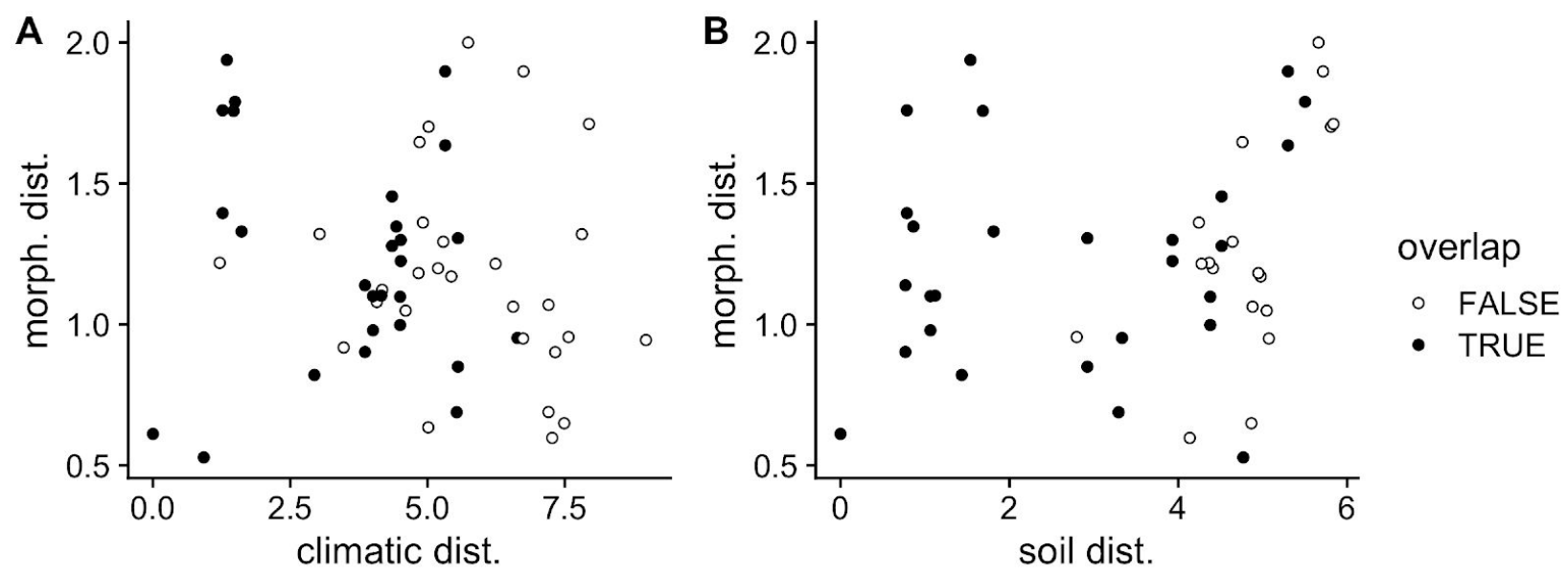

Figure 5: Pairwise species comparisons shown for (A) climatic distance between species versus morphological distance and $(B)$ soil distance between species versus morphological distance. Comparisons are coded by whether or not their geographic ranges overlap. Many species-pairs occur in similar ecological environments (i.e., they exhibit low soil or climatic distance) but still exhibit high morphological distance. 